Original Research

\title{
The Correlation between Nurses' Knowledge Regarding Patient Safety and Nurses' Behaviors in Drug Management
}

\section{Anita Rachmawati ${ }^{1}$}

1 Universitas Muhammadiyah Semarang, Indonesia

\section{Article Info}

Article History:
Submit May 26th, 2021
Accepted June 9th, 2021
Published June 23rd 2021
Keywords:
Behaviors; drug
management; knowledge;
patient safety

\section{INTRODUCTION}

Safety has become a global issue, including for hospitals. There are five important issues related to safety in hospitals, including patient safety, worker or health worker safety, building and equipment safety that affects patient and staff safety, environmental safety (green productivity) that affects environmental pollution, and hospital business safety that is related to the hospital survival.1 Implementing patient safety in hospitals is expected to minimize
Abstract

Nurses' knowledge regarding patient safety affects nurses' behaviors in managing drugs related to patient safety. A preliminary study at Sultan Agung Islamic Hospital Semarang showed that nurses' knowledge regarding patient safety was still low, especially about drug management, including storing, ordering/prescribing and recording, administering, and monitoring drugs. This study aimed to determine the correlation between nurses' knowledge regarding patient safety and nurses' behaviors in drug management among nurses in the inpatient units of Sultan Agung Islamic Hospital, Semarang. This research was an observational study with a crosssectional design. The population was 178 nurses in the inpatient units of the specified hospital with a total sample of 123 respondents. The data were collected using a questionnaire and analyzed using Spearman's rank correlation test. The results showed a correlation between nurses' knowledge regarding patient safety and nurses' behaviors in storing drugs $(\mathrm{p}=0.001<\alpha=0.05)$, ordering and recording drugs $(\mathrm{p}=0.000<\alpha=0.05)$, administering drugs $(\mathrm{p}=0.001<\alpha=0.05)$, and monitoring drugs $(\mathrm{p}=0.003$ $<\alpha=0.05)$. It is expected that nurses evaluate the drug management implementation in the inpatient units so that patient safety is guaranteed as well as plan and manage their behaviors in managing drugs in the hospital to ensure patient safety. 
technology, it is realized that health services, especially in hospitals, are becoming complex and have the potential for adverse events if not delivered carefully. Adverse events in hospitals can occur due to errors in administering drugs. There are hundreds of types of drugs, tests and procedures, tools with different technologies, and diverse professions and non-profession workers who are ready to provide 24-hour patient care. If not appropriately managed, the diversity and regularity of these services can lead to adverse events. ${ }^{4}$

A study by Auburn University in 36 hospitals and nursing homes in Colorado and Georgia, USA in 2002 showed that out of 3,216 types of drug administration, $43 \%$ were given at the wrong time, $30 \%$ were not given, $17 \%$ were given with a wrong dose, and $4 \%$ were given with wrong drugs. A study by the Institute of Medicine in 1999 also stated that medical errors had caused more than one million injuries and 98,000 deaths a year. The data obtained by JCAHO also showed that 44,000 and 98,000 deaths occur in hospitals each year due to medical errors. A report by the Institute of Medicine, USA, in 2000, "To Err Is Human: Building a Safer Health System," followed by WHO data in 2004 from various countries, reported that there were $3-16 \%$ of adverse events in the provision of services to inpatients in hospitals. Such a statistic is relatively small but has a significant impact on patient safety. 5,6

Data on the report of adverse events in the inpatient units of Sultan Agung Islamic Hospital Semarang showed that in 2012, there were incidents of medication errors that led to allergies in two patients; one of them died due to this incident. Furthermore, in 2013, other incidents of medication errors also occurred in eight patients; six experienced wrong drug administration, and two experienced drug allergies. This statistic showed a significant increase by $200 \%$ in the number of medication errors from 2012 to 2013.7 The implementation of the patient safety program in the hospital related to drug management was still suboptimal. In this regards, the problems included the patients dying due to allergies and wrong drug administration, wrong procedures in administering drugs, incorrect writing of prescriptions, and switched drugs between patients in the hospital. ${ }^{5}$

The results of observations and interviews with 12 nurses from four inpatient units in the hospital where this study too place showed that there were eight nurses $(66.6 \%)$ who did not understand how to administer the right drugs. Problems of drug management in the inpatient units included problems of storing drugs. There were the Look-Alike Sound-Alike (LASA) drugs in the inpatient units, but the placement was not separated. This situation can lead to errors in taking medicine. Problems with ordering and recording drugs in the inpatient units were associated with unclear or unreadable doctor's writing, making it difficult for nurses and pharmacists to immediately serve the patients' drugs since they had to reconfirm with the doctor who wrote the prescription. Problems in administering drugs in the inpatient units were related to nurses who did not wash their hands and re-identify patients before giving drugs, as well as administering wrong medication to other patients. Meanwhile, problems in monitoring drugs in the inpatient units were associated with nurses who did not conduct initial assessments related to allergies that might occur in patients after the patients took medication, and if allergies occurred, the nurses just knew it after the patients and families reported the incidents regarding drug allergies. ${ }^{8}$

\section{METHODS}

This research was a quantitative and observational study with a cross-sectional approach. It was conducted to determine the correlation between nurses' knowledge regarding patient safety and nurses' 
behaviors in storing, ordering and recording, administering, and monitoring drugs. 9 This study involved 123 nurses in inpatient units who met the inclusion and exclusion criteria. The exclusion criteria included: (a) nurses who were resting due to sickness and were unable to be involved in data collection, and (b) nurses who were on maternity leave. This study was conducted in the inpatient units of Sultan Agung Islamic Hospital Semarang.

The study was conducted in May 2014 for two weeks (the first to the second week). The data were collected by using a selfadministered questionnaire. The validity of the instrument was tested using content validity and construct validity. The reliability in this study was carried out using one shot or one measurement. Bivariate analysis was carried out on two variables that were suspected to be correlated. $^{10}$ The correlation test was conducted by ensuring whether the data had a normal or abnormal distribution. Since the number of samples was more than 50 , the Kolmogorov-Smirnov test was used to examine the data normality. ${ }^{11}$

The result of the normality test showed a pvalue of 0.000 for nurses' knowledge regarding patient safety and a p-value of 0.032 and 0.041 for nurses' behaviors in storing drugs and ordering and recording drugs, respectively. Furthermore, nurses' behavior in administering drugs and monitoring drugs showed a p-value of 0.000 and 0.010, respectively. It could be concluded that the data were abnormally distributed; therefore, the Spearman rank correlation was used to determine the correlation between the variables.

\section{RESULTS}

This study investigated the correlation between nurses' knowledge regarding patient safety and nurses' behavior in drug management in the inpatient units of Sultan Agung Islamic Hospital Semarang. This study involved 123 nurses from 10 inpatient units in the specified hospital. The hospital where this study took place is an Islamic hospital with 302 beds and 178 nurses ${ }^{12}$.

Table 1 describes the characteristics of respondents. The mean age was 27.79 years old, the youngest was 22 , and the oldest was 55. The median was 26. The average working period was 4.53 years, the longest was 30 years, and the lowest was one year. Most nurses obtained D3 of nursing education (87.8\%), while the remaining $12.2 \%$ obtained a bachelor of nursing education. The majority were female (82.9), and the remaining were male $(17.1 \%)$.

Table 2 illustrates the median value of the nurses' behavior in drug management, including storing (Median=27; MinMax=16-32), ordering and recording (Median=26; $\quad$ Min-Max=15-32), administering (Median=18; Min-Max=820), and monitoring (Median=24; MinMax=7-28). Furthermore, the median value of nurses' knowledge regarding patient safety was 10 (Min-Max=2-12).

\section{The correlation between nurses' knowledge regarding patient safety and nurses' behavior in storing drugs in the inpatient unit}

Table 3 shows a correlation between nurses' knowledge regarding patient safety and nurses' behavior in storing drugs in the inpatient units. The correlation coefficient of the Spearman test was 0.304 , showing a moderate and positive correlation between nurses' knowledge regarding patient safety and nurses' behavior in storing drugs; the better the nurses' knowledge, the better their behavior in storing drugs.

\section{The correlation between nurses' knowledge regarding patient safety and nurses' behaviors in ordering and recording drugs in the inpatient unit}

Table 4 shows a correlation between nurses' knowledge regarding patient safety 
and nurses' behavior in ordering and recording drugs in the inpatient unit. The correlation coefficient value of the Spearman test was 0.436 , indicating that the correlation was moderate and positive. It means that the better the nurses' knowledge regarding patient safety, the better their behavior in ordering and recording drugs.

\section{The correlation between nurses' knowledge regarding patient safety and nurses' behavior in administering drugs in the inpatient unit}

Table 5 shows a correlation between nurses' knowledge regarding patient safety and nurses' behavior in administering drugs in the inpatient unit. The correlation coefficient value of the Spearman rank test was 0.288 , indicating that the correlation

was weak and positive. It implies that the better the nurses' knowledge regarding patient safety, the better their behavior in administering drugs.

\section{The correlation between nurses' knowledge regarding patient safety and nurses' behavior in monitoring drugs in the inpatient unit}

Table 6 shows a correlation between nurses' knowledge regarding patient safety and nurses' behavior in monitoring drugs in the inpatient unit. The correlation coefficient value of the Spearman rank test was 0.270 , which means that the correlation was weak and positive. It implies that the better the nurses' knowledge regarding patient safety, the better their behavior in monitoring drugs.

Table 1

Characteristics of respondents $(n=123)$

\begin{tabular}{llcl}
\hline Characteristics & $\mathrm{f}$ & $\%$ & Mean \pm SD (min-max) \\
\hline Age & & & $27.79 \pm 3.88(22-55)$ \\
Length of work & & & $4.53 \pm 3.50(1-30)$ \\
Gender & & & \\
$\quad$ Male & 21 & 17.1 & \\
$\quad$ Female & 102 & 82.9 & \\
Education & & & \\
$\quad$ D3 & 108 & 87.8 & \\
S1 & 15 & 12.2 & \\
\hline
\end{tabular}

Table 2

Characteristics of variables $(\mathrm{n}=123)$

\begin{tabular}{lcccc}
\hline Variable & Mean \pm SD & Median & Modus & Min-Max \\
\hline Storing & $26.72 \pm 4.193$ & 27.00 & 32.00 & $16-32$ \\
Ordering & $26.45 \pm 3.978$ & 26.00 & 31.00 & $15-32$ \\
Administering & $17.44 \pm 2.63$ & 18.00 & 20.00 & $8-20$ \\
Monitoring & $24.22 \pm 3.599$ & 24.00 & 28.00 & $7-28$ \\
Knowledge & $10.08 \pm 1.528$ & 10.00 & 10.00 & $2-12$ \\
\hline
\end{tabular}

Table 3

The correlation between nurses' knowledge regarding patient safety and nurses' behavior in storing drugs

\begin{tabular}{ccc}
\hline r-count & z-count & p-value \\
\hline 0.304 & 3.36 & 0.001
\end{tabular}


Table 4

The correlation between nurses' knowledge regarding patient safety and nurses' behavior in ordering and recording drugs

\begin{tabular}{ccc}
\hline r-count & z-count & p-value \\
\hline 0.436 & 4.82 & 0.000 \\
\hline
\end{tabular}

Table 5

The correlation between nurses' knowledge regarding patient safety and nurses' behavior in administering drugs

\begin{tabular}{ccc}
\hline r-count & z-count & p-value \\
\hline 0.288 & 3.18 & 0.001 \\
\hline
\end{tabular}

Table 6

The correlation between nurses' knowledge regarding patient safety and nurses' behavior in monitoring drugs

\begin{tabular}{ccc}
\hline r-count & z-count & p-value \\
\hline 0.270 & 2.98 & 0.003 \\
\hline
\end{tabular}

\section{DISCUSSION}

\section{The correlation between nurses' knowledge regarding patient safety and nurses' behavior in storing drugs in the inpatient unit}

The result of the study showed that the correlation coefficient value of the Spearman rank test was 0.304, which means that there was a moderate and positive correlation between nurses' knowledge regarding patient safety and nurses' behavior in storing drugs in the inpatient unit. It means that the better the nurses' knowledge regarding patient safety, the better their behavior in storing drugs.

The nurses' behavior regarding patient safety programs is determined by their knowledge, attitudes, beliefs, and traditions. Also, the availability of facilities, attitudes, and behaviors of health workers will support and reinforce the formation of specified behaviors. Nurses who do not want to implement patient safety maybe because they do not know the benefits of the patient safety program for themselves (predisposing factors). Other reasons are probably because the facilities are not available and the equipment is incomplete (enabling factors), and that health workers or other community leaders around them have never provided examples/counseling about patient safety programs (reinforcing factors) ${ }^{8}$

Nurses who have good knowledge regarding patient safety will demonstrate good behavior in storing drugs so that the implementation of the patient safety program in the hospital can be achieved.

The result of the study regarding nurses' behavior in storing drugs in the inpatient unit showed that 113 (91.9\%) nurses always checked the names of similar types of drugs every day in the inpatient units. This is in line with the standard operating procedure (SOP) in the hospital, which states that the pharmacy officers provide the "Look-Alike Sound-Alike (LASA)" label on the drug container or package by making the drug name with a dose of more than one type in all pharmaceutical centers visible.

The result of the study also showed that 48 (39\%) nurses always checked the completeness of the types of emergency drugs in the inpatient unit. This is in line with the SOP in the hospital in this study. Pharmacy officers, nurses, and midwives 
increase their awareness of specially labeled drugs that will be given to patients.

\section{The correlation between nurses' knowledge regarding patient safety and nurses' behavior in ordering and recording drugs in inpatient unit}

The results of this study showed that the Spearman test's correlation coefficient value was 0.436 , which means that there was a moderate and positive correlation between nurses' knowledge regarding patient safety and nurses' behavior in ordering and recording drugs in the inpatient unit. It indicates that the better the nurses' knowledge regarding patient safety, the better their behavior in ordering and recording drugs.

The selection of drugs for patient treatment requires specific knowledge and experience. Each hospital is responsible for identifying knowledgeable and experienced persons according to the required standards and are also permitted under license, certification, statute, or regulation to prescribe or order medication. The hospital can set limits for prescribing or ordering drugs by individuals, such as controlled substances, chemotherapy agents, or radioactive and investigative drugs. The workers who are allowed to prescribe and order drugs are recognized by the pharmacy service or other people that dispense drugs. In emergency situations, the hospital can identify additional personnel who are permitted to prescribe or order drugs. ${ }^{8}$

Nurses with good knowledge will show good behavior in ordering and recording drugs in the hospital. In recording each patient receiving the drug, the medical record will contain a list of the drugs prescribed or ordered for the patient along with the dosage and the number of times the drug is administered, including the 'if necessary' drugs. If this information is recorded on a separate medication sheet, this sheet should be inserted in the patient's medical record when discharged or transferred. ${ }^{8}$

This study also showed that nurses separated the emergency drug substitutes from doctors after used by patients. This is in accordance with the SOP at the hospital, which states that pharmaceutical officers should separate drugs with more than one dosage according to the type of the drug supply.

\section{The correlation between nurses' knowledge regarding patient safety and nurses' behavior in administering drugs in the inpatient unit}

The results of this study showed that the Spearman test's correlation coefficient value was 0.288 , indicating a weak and positive correlation between nurses' knowledge regarding patient safety and nurses' behavior in administering drugs in the inpatient unit. It implies that the better the nurses' knowledge regarding patient safety, the better their behavior in administering drugs.

In managing drugs related to patient safety, nurses need to pay attention to the six correct principles of drug administration. These principles include: (1) the right patient, (2) the right drug, (3) the right dose, (4) the right time, (5) the right route, and (6) the right documentation. Such principles are required by nurses as a guideline for their actions as in the inpatient unit, nurses have to give various kinds of drugs to several different patients. The administration of drugs by nurses that considers the six right principles will affect the success of the patients' treatment and recovery. ${ }^{1}$

Administering drugs to treat a patient requires specific knowledge and experience. Each hospital is responsible for identifying any knowledgeable and experienced persons according to the required standards and are also permitted under license, certification, statute, or 
regulation to administer drugs. The hospital can set limits for prescribing or ordering drugs by individuals, such as controlled substances, chemotherapy agents, or radioactive and investigative drugs. In emergency situations, the hospital can identify any additional personnel who are permitted to administer drugs. ${ }^{8}$

The result of the study regarding nurses' behavior in storing drugs in the inpatient unit revealed that nurses always doublechecked the name of the drug between the prescription and the doctor's instructions every day. This is in line with the SOP in the hospital, which states that nurses review the drugs according to the SOP. This review includes checking the drugs with the seven correct principles (correct patient, correct drug, correct dose, correct time, correct method of administration, correct documentation, and correct information), ensuring the correctness of the patient and the drug by matching the patient's name and date of birth, visiting the patient's room while taking the drug to be delivered, and providing a written information sheet about the drug to the patient.

\section{The correlation between nurses' knowledge regarding patient safety and nurses' behavior in monitoring drugs in the inpatient unit}

The result of the study showed that the Spearman test's correlation coefficient value was 0.270 , indicating that the correlation between nurses' knowledge regarding patient safety and nurses' behavior in monitoring drugs in the inpatient unit was at a weak level. The direction was positive, which means the better the nurses' knowledge regarding patient safety, the better the nurses' behavior in monitoring drugs.

Nurses who have good knowledge will be able to perform the task to evaluate the effect of the treatment on patients' symptoms or disease, as well as blood count, kidney function, liver function, and other monitoring for selective drugs. Nurses will also be able to evaluate patients for adverse events based on monitoring and make an adjustment on the dose or type of drug, if necessary. Nurses should closely monitor the patient's response to the first dose of the drug given to this patient. Such monitoring is intended to identify the anticipated therapeutic responses and allergic reactions, unanticipated drug interactions, and changes in patient balance that will increase the risk of falls. ${ }^{8}$

The results of the study regarding nurses' behavior in storing drugs in the inpatient unit also showed that every time a nurse received a new patient, the nurse did an initial detection of drug side effects in the inpatient room. The nurse provided information and education to the patient and family about drugs causing side effects. The nurse also wrote in the medical record when the side effect of certain drugs occurred in the patient; the nurse recorded the drug side effect in a particular sheet. This is in accordance with the SOP in the hospital, which states that nurses open the patients' records and write on the pharmaceutical care sheet regarding the data related to the therapy (drugs, laboratory data, clinical data, diagnosis, and others). Nurses examine the drugs that the patients receive and make an analysis on the appropriateness of the choice of therapy, the effectiveness of the therapy, and the side effects that have occurred or are likely to occur.

\section{CONCLUSION}

This study concluded that there was a correlation between nurses' knowledge regarding patient safety and nurses' behavior in storing drugs, ordering and recording drugs, administering drugs, and monitoring drugs in the inpatient units in the hospitals. 


\section{ACKNOWLEDGMENTS}

The researcher would like to say thank you to all the participated as research respondents.

\section{CONFLICTS OF INTEREST}

Neither of the authors has any conflicts of interest that would bias the findings presented here.

\section{REFERENCES}

1. Depkes RI. Buku Panduan Nasional Keselamatan Pasien Rumah Sakit. Jakarta. 2006.

2. PERSI, KARS, KKP-RS. Membangun Budaya Keselamatan Pasien Rumah Sakit, Lokakarya Program KP-RS. 17 November 2006.

3. Emi, Suheimi. Etika Keperawatan: Aplikasi pada Praktek. Jakarta. EGC. 2006.

4. Direktorat Jenderal Bina Upaya Kesehatan Kementerian Kesehatan RI Dengan Komisi Akreditasi Rumah Sakit (KARS). Standar Akreditasi Rumah sakit. Jakarta. September 2011.

5. Kinnenger $\mathrm{T}$ \& Reeder L. Estabilishing for technology to reduce medication error is both a science and an art. January 2014. Retrieved from http://www.Brigmedical.com/media.
6. WHO. World Alliance for Patient Safety, Forward Programme. Geneva. 2004.

7. Rekam Medik. Laporan Tahunan Rekam Medik RSI Sultan Agung. Semarang. Rekam Medik. 2012-2013.

8. Nine Life Saving Patient Safety Solution. 3 January 2010. Retrieved from http://www.who.int.

9. Nursalam. Konsep Dan Penerapan metodologi Penelitian Ilmu Keperawatan, Pedoman tesis, Skripsi dan Instrumen Keperawatan. Edisi 2. Jakarta. Salemba. 2011.

10. Sugiyono. Metode Penelitian Kuantitatif, Kualitatif dan R\&D. Bandung. Alfabeta. 2012.

11. DA de Vaus, Survey in Social Research, 5th Edition (New South Wales: Allen and Unwin, 2002) p. 259.

12. Martini. Hubungan karakteristik perawat, sikap, beban kerja, Ketersediaan fasilitas dengan pendokumentasian Asuhan keperawatan di Rawat Inap BPRSUD Kota Salatiga. Tesis. Semarang: Undip. 2007.

13. Gibson. 2004. Perilaku Struktur dan Proses. Jakarta: Binarupa.

14. Suhaeni, Eni. 2005. Sikap Bidan Puskesmas Pasca Pelatihan Poned Terhadap Pelayanan Emerjensi Dasar, Kabupaten Brebes. (Tesis). Semarang: Undip. 